\title{
Intelligence as a Predictor of Impulse Control among New Entrants Studying in B.Sc. Nursing Disciplines
}

\author{
Rupali Dhananjay Sarode ${ }^{1}$, Vaishali Dinesh Tendolkar² \\ 1,2 Students Guidance Clinic, Datta Meghe Institute of Medical Sciences \\ (Deemed to Be University) Sawangi, Meghe, Wardha, Maharashtra, India.
}

\section{ABSTRACT}

\section{BACKGROUND}

Students from various medical and paramedical disciplines require above average intelligence to understand all the medical subjects and concepts as it deals with human body and human life. Students of nursing discipline have huge responsibility of learning cognitive, affective domain and psychomotor skills simultaneously. It is also observed that impulse control (patience) is absolute virtue of health professional courses including nursing profession. Impulsivity always causes undesirable consequences. Nursing professional students are expected to possess good impulse control. We wanted to assess the level of intelligence, level of impulse control and relationship between intelligence and impulse control among new entrants studying nursing profession.

\section{METHODS}

In this descriptive study, a sample size of 100, 50 males and 50 females, first year students of B.Sc. nursing discipline were selected purposively from Nagpur and Wardha districts of Maharashtra, India. All the participants completed scales pertaining to impulse control and intelligence using impulse control scale developed by Shrivastava and Naydoo and Culture fair intelligence test by Cattle.

\section{RESULTS}

It shows that nursing boys significantly had more scores for intelligence $(\bar{x}=88.66)$ and for impulse control $(\bar{x}=206.62)$ than nursing girls $(\bar{x}=88.10),(\bar{x}=196.80)$ respectively. There exists a statistically non-significant positive relationship between intelligence and impulse control for overall population $(\mathrm{r}=0.153, \mathrm{P}<0.05)$. The findings suggest that higher the intelligence, greater is the impulse control among new entrants of nursing discipline.

\section{CONCLUSIONS}

Male students show more intelligence and had more impulse control as compared to nursing girls and also show greater magnitude of positive correlation as compared to their female counterparts.

\section{KEY WORDS}

Intelligence, Impulse Control, Relationship
Corresponding Author: Dr. Rupali Dhananjay Sarode, Department of Clinical Psychology, Jawaharlal Nehru Medical College, Sawangi Meghe, Wardha, Maharashtra, India.

E-mail: rupali27sarode@gmail.com

DOI: $10.14260 /$ jemds/2021/272

How to Cite This Article:

Sarode RD, Tendolkar VD. Intelligence as a predictor of impulse control among new entrants studying in B.Sc. nursing disciplines. J Evolution Med Dent Sci 2021;10(18):1286-1290, DOI: $10.14260 /$ jemds $/ 2021 / 272$

Submission 26-10-2020,

Peer Review 27-02-2021,

Acceptance 06-03-2021,

Published 03-05-2021.

Copyright (C) 2021 Rupali Dhananjay Sarode et al. This is an open access article distributed under Creative Commons Attribution License [Attribution 4.0 International (CC BY 4.0)] 


\section{BACKGROUND}

All the health professional courses are very exhaustive. The students of these courses experience counterproductive stress due to tough and vast syllabus which requires hard and sincere work. Health professional courses include medical, dental, ayurvedic, homeopathy, paramedical courses, pharmacy, physiotherapy and nursing.

Students from various medical and paramedical disciplines require above average intelligence to understand all the medical subjects and concepts as it deals with human body and human life. Intelligence is an umbrella term describing a property of the mind including related abilities, such as the capacities for abstract thought, understanding, communication, reasoning, learning, and learning from past experiences, planning and problem solving. The purpose of this study is also to investigate the expected level of intelligence required in new entrants pursuing health professional courses.

Students of nursing discipline have huge responsibility of learning cognitive, affective domain and psychomotor skills simultaneously. It is also observed that impulse control (patience) is an absolute virtue of health professional courses including nursing profession. Nursing professional students are expected to possess good impulse control.

The nature of nursing course creates a high level of anxiety, burnout, personal distress and sometimes depression. Among all the health professional courses, nursing profession play a major role in community. For a patient, nurse is a pillar of strength. A nurse is a health care professional who is in contact with the patient around a clock and is responsible for treatment, safety, and recovery and overall care of the patient.

Nursing students face not only academic stress but also distress while learning about clinical skills. A study conducted by Mortos, Landa and Zafra found that the most common sources of stress relate to academics (reviews, workload and problems associated with studying) and other sources of stress include clinical sources (such as fear of unknown situations, mistakes with patients or handling of technical; equipment's). ${ }^{1}$

Hence, such a profession requires good level of intelligence and good impulse control as nursing professional course consists both theoretical as well as clinical part. In theory class nursing students learn through lectures, case studies, interactive discussions and in clinical part, students have to learn and perform various nursing techniques and skills.

Stoddard tried to define intelligence as "the ability to undertake activities that are difficult, complex, and abstract, which are adaptive to a goal and are done quickly and which have social value and which lead to the criterion of something new and different." 2

It is found that with the above-average intelligence, it is observed that patience is absolutely virtue of students enrolled for health professional courses. Shrivastava and Naydoo observed that the concept of impulse control is often referred to as self-control and sometimes self-regulation. A striking feature of human behaviour is that people impose restrictions on themselves, interrupting their own activities and delaying the available gratification. When the delay of gratification is imposed on the individual by external forces, we talk of "frustration," and when the delay is self-imposed, we call it "self-control." 3 Whiteside \& Lynam, (2000) reported that the four personality facets associated with impulsive-like behaviours which were labelled urgency, (lack of) premeditation, (lack of) perseverance and sensation seeking. ${ }^{4}$

Ferraro et al. (2008), reported college students in U.S. scored low on measures of impulse control and executive functioning and high on measures of pathological gambling behaviour. ${ }^{5}$ Odlang, Grant, (2009) found 10.4 percent college students met criteria for at least one lifetime impulse control disorder. The most common disorders were trichotillomania (3.91\%) and compulsive sexual behaviour (3.66 \%), kleptomania was least common (0.38 \%). Males were significantly more likely to screen positive for pathological gambling and compulsive sexual behaviour. Females were more likely to have compulsive buying. ${ }^{6}$ Ford and Blumenstein reported that college students with low self-control were at greater risk for reporting binge drinking, marijuana use, and when students reported greater opportunities to use and also reported substance use by their friends. ${ }^{7}$

The researcher did not find any studies done on new entrants of B.Sc. nursing students for the two variables, namely, intelligence and impulse control.

\section{Objectives}

1. To study the relationship between intelligence and impulse control among new entrants studying in nursing discipline.

2. To assess level of intelligence, to assess the level of impulse control and to identify relationship between intelligence and impulse control among new entrants studying B.Sc. nursing discipline.

\section{METHODS}

This is a descriptive study conducted from September 2014 to December 2014 on the new entrants of B.Sc. nursing students both males and females from private colleges of Wardha and Nagpur district. There were three nursing colleges selected for this study from Wardha and Nagpur district. The study is conducted in student's guidance clinic, a counselling clinic of Medical University, DMIMSU, Sawangi (M) Wardha.

Sampling technique was purposive sampling. A total of 100 (50 males and 50 females) students were selected.

In India $30 \%$ male students are allowed in the nursing professional courses as per the apical council norms. However, the profession is not very popular among the students. Nursing is primarily a female dominated profession. The investigator felt that proportionate representation of males may not be actually representing the male nurse students. Hence, the sample size is restricted to 100 with equal proportion of males and females.

\section{Material for Data Collection}

- Demographic data sheet

- The demographic information of the students includes age, residence, course of the study, type of family members, choice of health profession etc.

- Culture fair intelligence test: Scale 2, Form A, by Raymond Cattle and Karen Cattle. This test measures fluid 
intelligence, each scale contains 4 subtest-series, classification, matrices and conditions. ${ }^{8}$

- Impulse control scale

Impulse control scale (I.C.) by Anjali Shrivastava and R.K. Naidu. It contains 65 statements. It is a paper pencil selfreport measures of impulse control using Likert type 5point scale ranging from "never" (score 1) to "always" (scored 5). ${ }^{3}$

\section{Method of Data Collection}

The permission of the college authorities was obtained before conducting the study. Prologue of the study given to the students in their college settings. Doubts regarding the study were clarified. Written consent was taken; both the tools administered one after other. All the instructions and protocols of administration for each tool were followed strictly. Data was collected by data collectors simultaneously in three colleges to avoid contamination. Average time taken to complete the data sheets was 40 minutes approximately.

\section{Statistical Analysis}

Investigators followed all the instructions given in the test manuals and scored accordingly. The SPSS 17 version (SPSS Inc. 233 South Wacher Drive Analysis, $11^{\text {th }}$ floor, Chicago, II, USA 60606 - 6412) was used for inferential data analysis and for further descriptive statistics such as means and standard deviation for all variables used in the study is done. A correlation matrix was obtained to examine the relation between the variables.

\section{RESULTS}

The present study was designed to assess the relationship between intelligence and impulse control among entrants of B.Sc. nursing. The analysis of the data done as per the objectives of the study.

Table 1 shows the distribution of students according to their demographic characteristics. Total 100 students were the participants and were in the range of 17 - 19 age groups. $88 \%$ students belonged to nuclear family type and $12 \%$ students belonged to joint family type. $76 \%$ students were Hindu, $03 \%$ students were Christian, and $21 \%$ students were Buddhist. Among the participants, $51 \%$ students were $1^{\text {st }}$ child, $36 \%$ students were second child, $10 \%$ students were third child, $2 \%$ students birth order was $4^{\text {th }}$ and $1 \%$ students were $6^{\text {th }}$ child. $6 \%$ students had conflict between family members once in a week, $33 \%$ students had conflict between family members once a month, $6 \%$ students reported conflict between once in a fortnight and $55 \%$ reported they never faced any conflict between family members. $75 \%$ students have chosen B.Sc. nursing by themselves, $15 \%$ students by their parents wish. $1 \%$ students reported that they have selected this profession due to their friends, $4 \%$ students selected due to relatives and $5 \%$ students selected this nursing profession due to both self and parents.

Table 2 shows the mean score of culture fair intelligence test-CFIT (intelligence). The nursing boys (X $=88.66$ ) score significantly higher than nursing girls $(X=88.10)$ this reflects that nursing boys shows more intelligence than nursing girls.
Similarly, the mean score of impulse control of nursing boys $(X$ $=206.02)$ score significantly higher than nursing girls $(\mathrm{x}=$ 196.8). This also shows that the nursing boys had more control on their impulses than girls. The correlation between intelligence and impulse control between male and female new entrants $(n=100)$ of B.Sc. Nursing discipline showed statistically non-significant positive correlation $(\mathrm{r}=0.153, \mathrm{P}>$ $0.05)$. It was also seen that there was a statistically nonsignificant positive relationship among males $(\mathrm{r}=0.194, \mathrm{P}>$ $0.05)$ and among females ( $r=0.122, P>0.05)$. It is showed that higher the intelligence, more the impulse control.

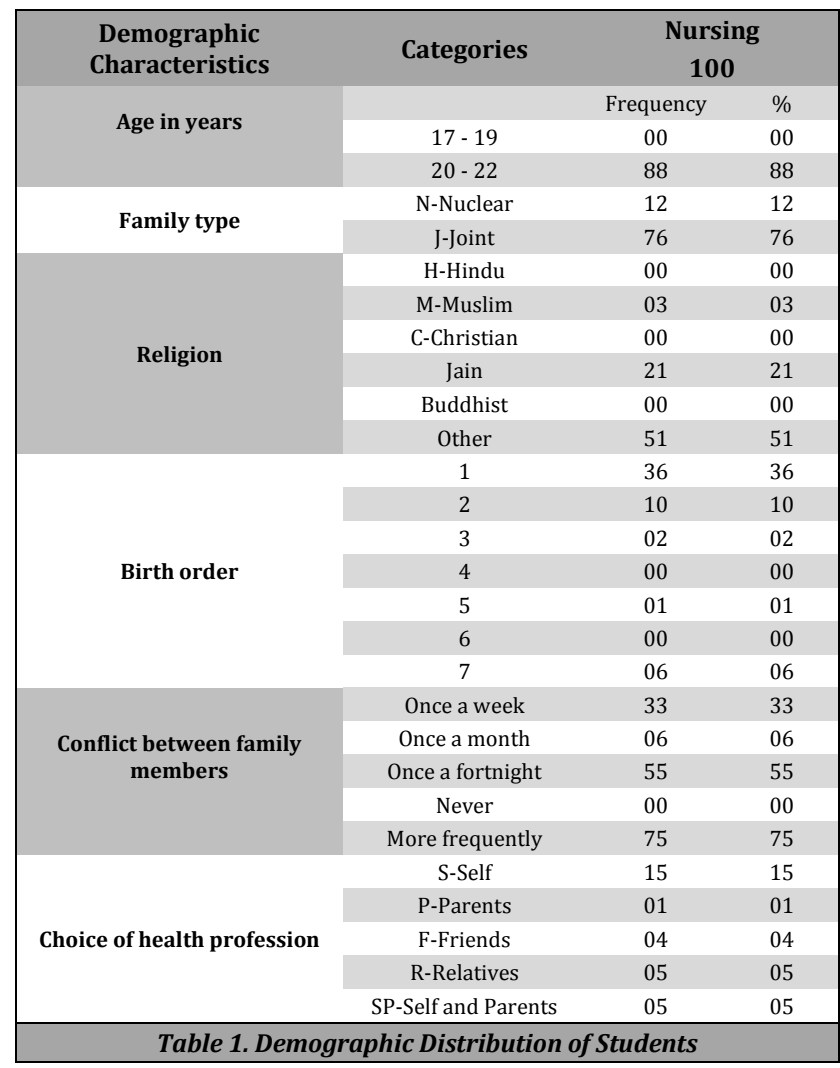

\begin{tabular}{|cccccc|}
\hline $\begin{array}{c}\text { Population } \\
\text { Group }\end{array}$ & $\begin{array}{c}\text { IQ Mean + } \\
\text { SD }\end{array}$ & $\begin{array}{c}\text { Impulse Control } \\
\text { Mean + SD }\end{array}$ & N & $\begin{array}{c}\text { Correlation } \\
\text { ' } \mathbf{r} \text { ' }\end{array}$ & $\begin{array}{c}\text { P- } \\
\text { Value }\end{array}$ \\
Nursing boys & $88.66+8.90$ & $206.62+19.31$ & 50 & 0.194 & $0.177 \mathrm{NS}$ \\
Nursing girls & $88.10+11.72$ & $196.80+21.74$ & 50 & 0.122 & $0.398 \mathrm{NS}$ \\
Overall nursing & $88.38+10.36$ & $201.71+21.05$ & 100 & 0.153 & $0.129 \mathrm{NS}$ \\
\hline \multicolumn{5}{|c|}{ Table 2. Correlation between Impulse Control } \\
and IQ among Nursing Boys and Girls
\end{tabular}

\section{DISCUSSION}

The aim of the present study is to identify the relationship between intelligence and impulse control among new entrants studying in B.Sc. nursing course. Male students show more intelligence $(88.66+8.90)$ and had more impulse control $(206.62+19.31)$ as compared to nursing girls $(88.10+11.72)$, $(196.80+21.74)$. There is non-significant positive correlation between intelligence and impulse control, which indicates that higher the intelligence more the impulse control and also show greater magnitude of positive correlation as compared to their female counterparts. In a study of Mitthal K (2017) titled 'A Study of general intelligence among Degree College Students' reported that $20 \%$ students have average intelligence, $45 \%$ 
students have below average and $35 \%$ students have above average general intelligence and also show contradictorily male and female students do not differ significantly in their general intelligence. ${ }^{9}$

Impulse control or self-control is central function of the self and important key to success in life. Impulsivity and intelligence are interrelated and interdependent. Mangal (2006) referred intelligence as ability to learn, deal with abstraction, ability to make adjustment and make appropriate responses to certain stimuli in given situation or adapt to new situation. ${ }^{10}$ These findings are supported by the study conducted by Bertucci J (2020) which suggested that inability to delay gratification is evident in non-traditional nursing students who work full time.11 Pfefferbaum B \& Wood P observed that male students had high self-control or thrill seeking behaviour and low self-control for property delinquency. ${ }^{12}$ In another study titled 'Impulsiveness and risktaking behaviour: Comparison of high-school and college students using the Barratt Impulsiveness Scale' conducted by Standford S, Greve Kevin, Boudreauk J, Mathias C and Brumbelow J., revealed that high impulsive adolescents and young adults are at considerable risk of personal injury and present a potential source of injury to others. ${ }^{13}$

Sarode and Tendolkar (2019) who found that there is a positive correlation between impulse control and intelligence among new entrants studying in various medical disciplines. ${ }^{14}$ But in contradictorily in another study by Collet and Vives, who found that there is an inverse correlation between impulsivity and intelligence and also found positive correlation between impulsivity and academic failure. ${ }^{15}$ Wolfe and Higgins (2008) reported largest correlation between selfcontrol and drinking peers. Self-control has a significant negative link with drinking alcohol. ${ }^{16}$

The findings of another study by Lozano et. al. suggests that among the university students age ranged from $18-37$ years, there was negative relationship between impulsivity and intelligence. ${ }^{17}$

A study by Lynam, Moffitt, Loeber (1993) found that impulsivity was more to related verbal intelligence than to performance intelligence which shows that dysfunction at an executive level that greatly interfere with self-control. ${ }^{18}$ Study conducted by Bonavila S., Vives F., Cosi S. and Colet A. (2017) observed that impulsivity and intelligence showed a different pattern of relationships with different forms of aggression. While intelligence measures were more related to indirect aggression, particularly to the g factor estimate, impulsivity was more related to direct forms of aggression. ${ }^{19}$

\section{CONCLUSIONS}

The study findings reveal that higher the intelligence greater is the impulse control among new entrants of nursing discipline. Further the boys in nursing discipline show higher impulse control as compared to their female counterparts. This indicates that the nursing students need to improve their intellect in order to be more composed nurse professionals. Females who aspire to be nurses need to learn strategies to improve their impulse control. A study is recommended with standard psychotherapies for impulse control as intervention among nursing students.

\section{Ethical Clearance}

Ethical clearance is obtained from the Research and Recognition Committee of Nagpur University. (Vide Reference no: Ph.D. (Cell) / RRC / 652)

Data sharing statement provided by the authors is available with the full text of this article at jemds.com.

Financial or other competing interests: None.

Disclosure forms provided by the authors are available with the full text of this article at jemds.com.

\section{REFERENCES}

[1] Pulido-Martos M, Augusto-Landa JM, Lopez-Zafra E. Sources of stress in nursing students: a systematic review of quantitative studies. International Nursing Review 2011;59(1):15-25.

[2] Stoddard GD. The meaning of intelligence. New York: Macmillan Co, 1943.

[3] Shrivastava A, Nayadoo R. Manual for Impulse Control Scale. Varanasi: Manovaigyan Parikshan Sanstha 1987.

[4] Whiteside SP, Lynam DR. The five factor model and impulsivity: using a structural model of personality to understand impulsivity. Journal of Personality and Individual Differences 2001;30(4):669-9.

[5] Ferrao R, Gourneau M, Clow K, et al. Impulse control, executive functioning and gambling in college students. Psychology Academic Journal 2008;5(4):212-4.

[6] Odlang BL, Grant JE. Impulsive- control disorders in a college sample: results from the self-administered Minnesota impulse disorder interview. Prim Care Companion Clin Psychiatry 2010;12(2):PCC.09m00842.

[7] Ford J, Blumenstein L. Self-control and substance use among college students. J Drug Issues 2013;43(1):56-68.

[8] Cattle RB. Measuring intelligence with culture fair tests Manual for scale 2 \& 3. New Delhi: Psycho Centre 1973.

[9] Mittal K. A study of general intelligence among degree college students. An Int J of Education and Applied Social Science 2017;8(3):775-9.

[10] Mangal SK. General Psychology. Stering Publishers Private Limited., 2006.

[11] Bertucci J. Impulsivity as a trait predictor in baccalaureate nursing students. Dissertation, University of Southern Mississippi 2020.

[12] Pfefferbaum B, Wood PB. Self-report study of impulsive and delinquent behavior in college students. J Adoles Health 1994;15(4):295-302.

[13] Standford S, Kevin G, Boudreauk J, et al. Impulsiveness and risk-taking behavior: comparison of high-school and college students using the Barratt impulsiveness scale. Personality and Individual Differences 1996;21(6):10735.

[14] Sarode R, Tendolkar V. Relationship between intelligence and impulse control among new entrants studying in various medical disciplines. Journal of Datta Meghe Institute of Medical Sciences University 2019;14(4):33841.

[15] Vigil-Collet V, Morales-Vives F. How impulsivity is related to intelligence and academic achievement. Span J Psycho 2005;8:199-204. 
[16] Wolfe SE, Hinggins GE. Self-control and perceived behavioral control: an examination of college student drinking. Applied Psychology in Criminal Justice 2008;4(1):109-34.

[17] Lozano JH, Gordillo F, Pérez MA. Impulsivity, intelligence and academic performance: testing the interaction hypothesis. Personality and Individual Differences 2014;62:63-8.
[18] Lynam D, Moffitt T, Stouthamer- loeber M. Explaining the relations between intelligence and delinquency: class, race, test, motivation, school failure and self control? J Abnorm Psychol 1993;102(3):187-96.

[19] Duran-Bonavila S, Morales-Vives F, Cosi S, et al. How impulsivity and intelligence are related to different forms of aggression? Personality and Individual Differences 2017;117:66-70. 